\title{
Petrified auricular cartilages pointing the diagnosis of post-partum hypopituitarism in an encephalopathic patient
}

\author{
Álvaro Machado $\cdot$ Maria Lopes · Carla Ferreira
}

Received: 22 November 2007 / Accepted: 18 March 2008 / Published online: 28 March 2008

(C) Springer-Verlag 2008

\begin{abstract}
True ossification of ear auricles is exceptional. We present the first case linking this finding to post-partum hypopituitarism. A 57-year-old female presented with a 2-day history of fever, headache and behavioural disturbances. Brain magnetic resonance imaging was normal. Since cerebral spinal fluid could not be obtained, she was treated empirically for a meningitis. A urinary tract infection was subsequently identified as the cause of fever but when she improved she remained apathetic. At this time petrified auricles were noticed; histological examination revealed true ossification. Endocrinological screening showed partial hypopituitarism and thyroid autoimmune disorder. Initial symptoms could be dated to the birth of her last child 15 years before, with breast feeding difficulties, loss of body hair, and transient amenorrhoea. The absence of overt peripartum bleeding, resumption of menses 1 year later, preservation or recovery of some hypophyseal function, and presence of an associated autoimmune thyroid disorder and of hypophyseal tissue in a normal sella turca, all suggest lymphocytic hypophysitis rather than Sheehan syndrome as the primary disorder. Of the 15 patients reported to date with auricular ossification, two had Addison disease. The present case suggests that low cortisol is the key factor in this clinical finding.
\end{abstract}

\footnotetext{
Á. Machado · C. Ferreira $(\square)$

Neurology Department, Hospital de São Marcos, Largo Carlos Amarante, Apartado 2242,

4701-965 Braga, Portugal

e-mail: carla.m.c.ferreira@gmail.com

M. Lopes

Endocrinology Department, Hospital de São Marcos,

Braga, Portugal
}

Keywords Encephalopathy - Auricular ossification . Hypopituitarism

\section{Introduction}

Petrified ear auricles are rarely encountered in clinical practice. They may represent true ossification but this is exceedingly rare [2]. More often, they are due to calcification of auricular cartilages, which can only be distinguished from true ossification on histological examination.

Post-partum hypopituitarism can occur in two conditions: Sheehan syndrome and lymphocytic hypophysitis [4]. We present the first case linking post-partum hypopituitarism with true ossification of the ear auricles.

\section{Case report}

A 57-year-old female presented with a 2-day history of fever, headache and behavioural disturbances. Past medical history was notable for long-lasting depression and osteoarticular disease. When examined she was febrile, drowsy, and had inappropriate speech and cervical rigidity (in all directions). Brain magnetic resonance imaging (MRI) was normal. Cerebral spinal fluids (CSF) could not be obtained at that time. She was, therefore, empirically treated with antibiotic and antiviral drugs. However, by day 4, there was no change in her clinical condition. Radiographic-guided spinal tap disclosed normal CSF. At the same time, a mid-stream urine showed increasing leucocyturia. This prompted appropriate antibiotic therapy, with gradual improvement, such that the patient was afebrile and fully conscious at day 6 .

Although the family said she was back to normal, she appeared to us to be apathetic, globally slowed, and to lack 
initiative. We noted that the patient had postural hypotension and also auricular rigidity, such that her ears moved all in one piece. No other dermatological local abnormality was found. There was no history of trauma or cold exposure. Patient and family were surprised with our interest in something that had occurred over the last decade and that had never really been noted. Dermatological examination did not show any other sign of cartilage calcification, but lack of axillary and pubic hair was evident. Simple X-ray was notable for complete auricular petrification (Fig. 1a) and histological exam revealed true ossification, with lamellar bone, haversian channels, and bone marrow tissue (Fig. 1b).

Laboratory study revealed hypopituitarism: low adrenocorticotropic hormone with undetectable cortisol, low growth hormone releasing-hormone, and thyroid-stimulating hormone, with preserved luteinizing and follicle-stimulating hormones. She had auto-antibodies to thyroid gland.
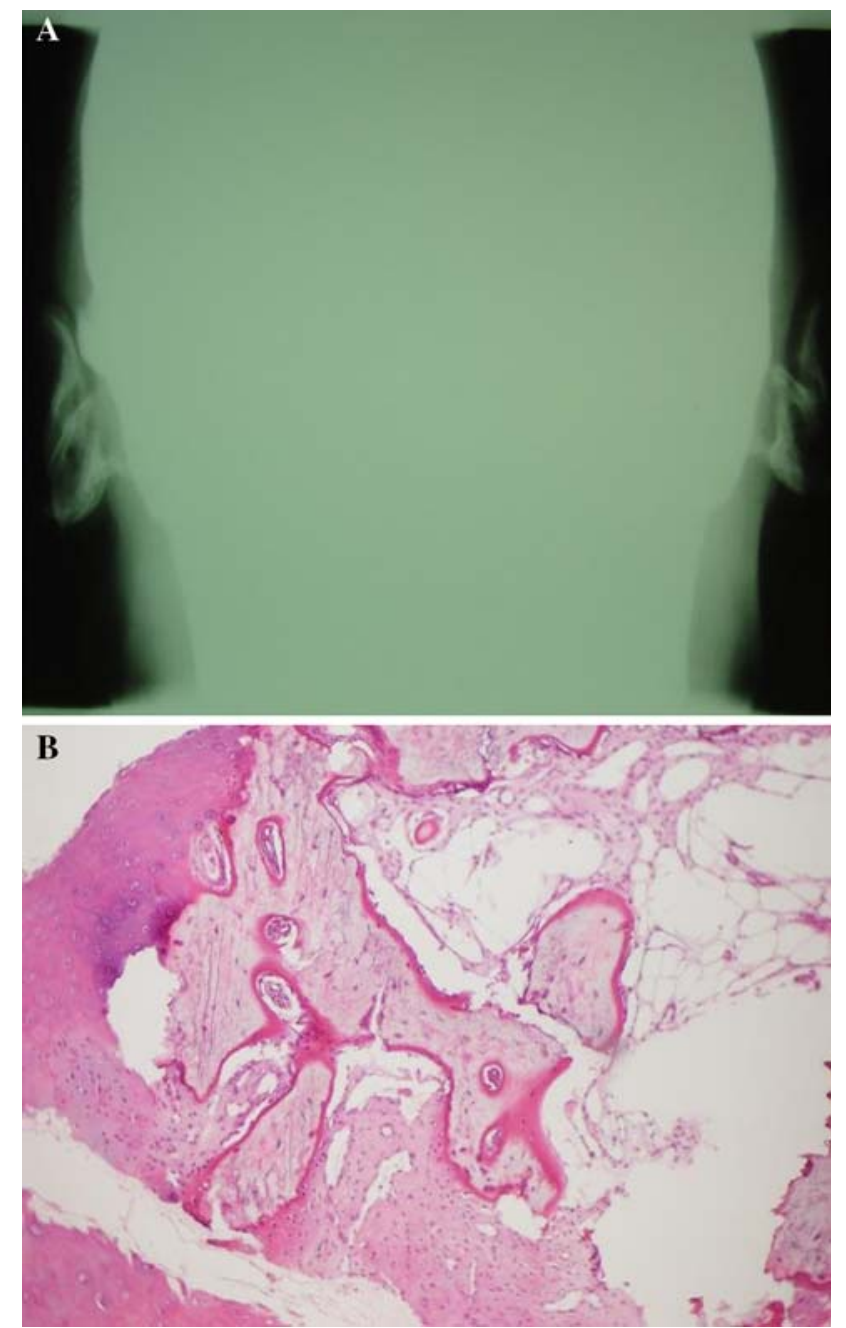

Fig. 1 a Simple X-ray shows complete auricular petrification. b Histological exam reveals lamellar bone with haversian channels and bone marrow tissue
Her phosphocalcium metabolism was normal. Hypophyseal directed MRI showed a small gland with normal signal intensity.

Further questioning of her family revealed that the beginning of her depressive symptoms could be dated to 14 years previously, soon after her last delivery; when one of her sons had died. That delivery had been in the hospital-no excessive blood lost was reported and she had been discharged on day 3. However, she could not breastfeed the newborn because "she had no milk". Since then she had been indifferent, sad, and "always in bed". She restarted menses 1 year later, but lost body hair and her "ears got harder and harder".

Hormonal replacement resulted in astonishing improvement, revealing a funny, active and talkative person who said one day: "I've already lost 15 years of my life; I don't want to lose another!" Her ears remain unchanged.

\section{Discussion}

Auricular petrification is an exceedingly rare phenomenon, with about 150 cases reported [2]. Scherrer examined 800 patients and did not find it. Gordon examined $300 \mathrm{X}$-rays finding 11 cases, but none with clinical evidence of it [2]. Most times, auricular petrification occurs progressively over several years and is asymptomatic or little noted. Rarely, local pressure, ulceration, and hearing difficulties can result $[2,3]$.

Auricular petrification can follow calcification or, much more rarely, ossification. The latter refers to substitution of cartilage by lamellar bone and can only be diagnosed histologically. There are 15 patients with auricular ossification reported: only one symptomatic and two of them with Addison disease [1-3].

Central hypopituitarism has not been reported as causing auricular ossification, although in four cases it has been related to auricular calcification without histological examination being performed [5]. Association between central and peripheral hypopituitarism and auricular petrification suggests that low serum cortisol could be the pathophysiologic key factor $[2,5]$. Both hypercalcemia and hyperphosphatemia can occur in adrenergic insufficiency and some authors believe that even transitory disturbances can be sufficient in inducing ectopic ossification [2]. This could explain the normal phosphocalcium metabolism in our patient.

There are two causes of partum-related hypopituitarism [4]: Sheehan syndrome, referring to extensive haemorrhage resulting in adeno-hypophysis ischemia, and lymphocytic hypophysitis, a rare condition in which auto-antibodies against hypophyseal tissue can be found, leading to gland lymphocytic infiltration and subsequent dysfunction. 
In the present patient, absence of overt peripartum bleeding, resumption of menses (1-year post-partum), preservation or recovery of some hypophyseal function, and presence of an associated autoimmune thyroid disorder and of hypophyseal tissue in a normal sella turca, all suggest lymphocytic hypophysitis as the primary disorder.

Acknowledgments The authors thank Michael Eddleston, MD, $\mathrm{PhD}$, for carefully reviewing the manuscript, Fernando Pardal, MD, Anatomopathology Department, Hospital de São Marcos, Braga, Portugal and Teresa Pereira, MD, Dermatology Department, Hospital de São Marcos, Braga, Portugal.

Conflict of interest statement The authors report no conflict of interests.

\section{References}

1. González-Sixto B, Garcia-Doval I, Conde A et al (2006) Bilateral ossification of the auricular cartilag. Actas Dermosifiliogr 97(2):134-5

2. High WA, Larson MJ, Hoang MP (2004) Idiopathic bilateral auricular ossificans: a case report and review of the literature. Arch Pathol Lab Med 128(12):1432-4

3. Manni JJ, Berénos-Riley LC (2005) Ossification of the external ear: a case report and review of the literature. Eur Arch Otorhinolaryngol 262(12):961-4

4. Seshadri KS, Cowan BD (2007) Pituitary disease and pregnancy. http://www.emedicine.com/med/topic3264.htm. Accessed April 2007

5. Wang CY, Chang TC, Chen FW (2002) Ossification of the auricles: a forgotten sign in adrenal insufficiency. J Otolaryngol 31(1):52-4 